\title{
Estudo comparativo da densidade de células endoteliais da córnea após facoemulsificação pelas técnicas de "dividir e conquistar" e "quick chop"
}

\author{
Corneal endothelial cell density comparative study after phacoemulsification by "divide \\ and conquer" and "quick chop" techniques
}

\author{
Flavia Guedes Pinto Domingues ${ }^{1}$ \\ Haroldo Vieira de Moraes Jr. ${ }^{2}$ \\ Riuitiro Yamane ${ }^{3}$
}

Trabalho realizado no Hospital Universitário Clementino Fraga Filho, Faculdade de Medicina da Universidade Federal do Rio de Janeiro, Departamento de Oftalmologia.

${ }^{1}$ Médica Oftalmologista, mestre em medicina pela Universidade Federal do Rio de Janeiro - UFRJ.

${ }^{2}$ Professor Doutor do Departamento de Oftalmologia e Coordenador de Pós-graduação em Oftalmologia da Universidade Federal do Rio de Janeiro - UFRJ, LivreDocência em Oftalmologia pela Universidade Federal de São Paulo - UNIFESP.

${ }_{3}^{3}$ Professor Titular do Departamento de Oftalmologia da Universidade do Estado do Rio de Janeiro - UFRJ

Endereço para correspondência: Flavia Guedes Pinto Domingues - Av. Sernambetiba, 3600, Bloco 6/1304 Rio de Janeiro (RJ) CEP 22630-010

E-mail: fmingues@hotmail.com

Recebido para publicação em 01.11.2002

Versão revisada recebida em 03.06.2003

Aprovação em 11.11.2004

\begin{tabular}{|c|}
\hline RESUMO \\
\hline 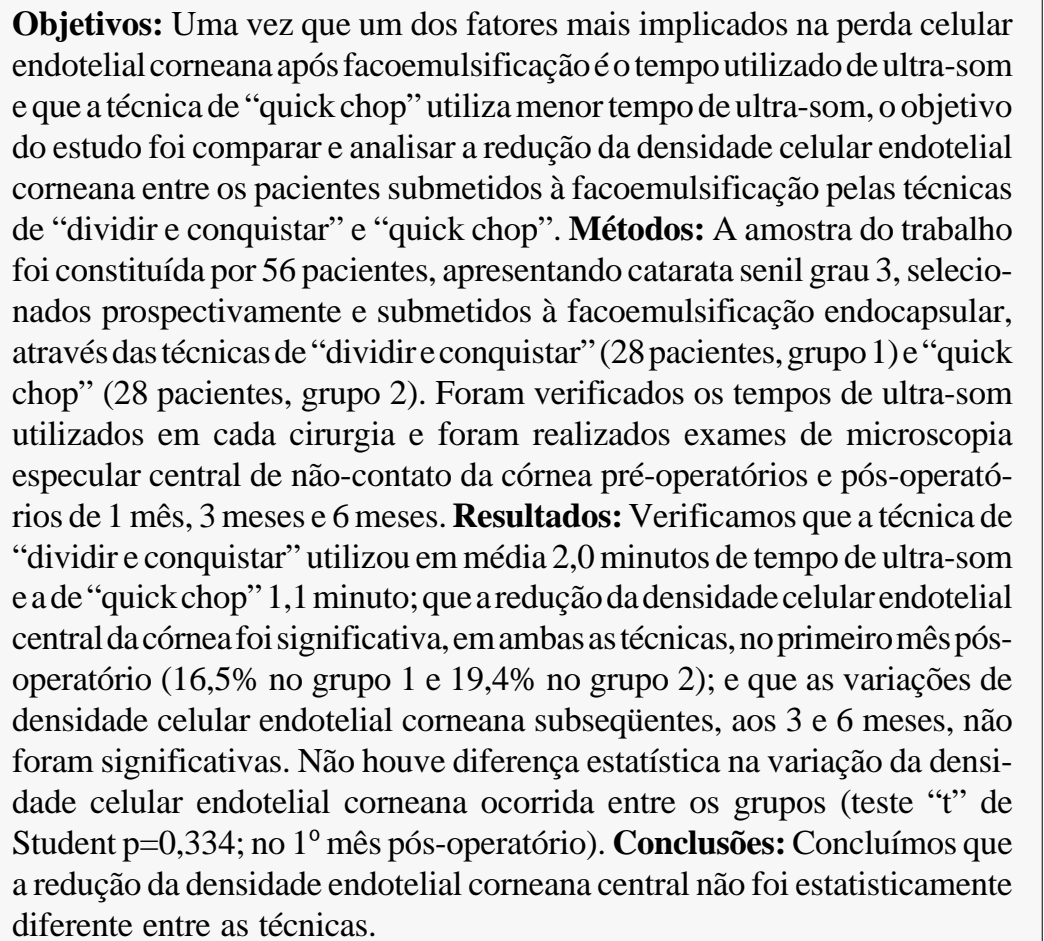 \\
\hline
\end{tabular}

Descritores: Extração de Catarata/métodos; Facoemulsificação; Contagem de células; Endotélio da córnea; Estudo comparativo

\section{INTRODUÇÃO}

As máquinas mais modernas de facoemulsificação são capazes de remover a catarata utilizando parâmetros elevados de vácuo e fluxo de aspiração e baixa quantidade de energia ultra-sônica ${ }^{(1-3)}$. Elas permitiram o surgimento de técnicas bastante rápidas na extração da catarata, como a técnica de "quick chop"(4-7), também conhecida por "chop vertical” (comunicação pessoal").

Vladmir Pfeifer"*, cirurgião da Eslovênia, descreveu a técnica como uma

*Crema AS. Comunicação pessoal. 2001.

***Vladmir Pfeifer apud ${ }^{(5)}$. 
modificação do "phaco-chop" de Nagahara, e a chamou de "phaco crack"(4-7).

Dillman publicou a técnica e chamou-a de "quick chop". Referiu que tal técnica é realizada com o uso de alto vácuo, pouca quantidade de ultra-som e um "chopper" pontiagudo ${ }^{(4)}$. O "chopper" e a ponteira de facoemulsificação são cravados lado a lado no centro do cristalino. A fratura da catarata ocorre através de uma manobra bimanual vigorosa, pela qual o "chopper" é deprimido e a ponteira elevada no centro do cristalino e, simultaneamente, os instrumentos são afastados lateralmente. Após a fratura, torna-se mais fácil a remoção da catarata.

O trauma cirúrgico ocorrido durante a facoemulsificação leva à perda de células endoteliais da córnea. Como essas células não se regeneram, a maioria dos estudos que avaliam a segurança de novas técnicas envolvem a avaliação da redução da densidade celular endotelial corneana à microscopia especular ${ }^{(2,8-16)}$.

Os fatores associados à perda de células endoteliais corneanas causada pela facoemulsificação são vários e incluem o tempo de ultra-som utilizado na cirurgia, a turbulência de líquido na câmara anterior e o trauma mecânico ${ }^{(17-22)}$.

A técnica de "dividir e conquistar", modificada por Shepherd em 1990, é bastante popular por ser bem sistemática, utiliza maior quantidade de ultra-som do que a de "quick chop" e não necessita de vácuo tão elevado(23-26). Crema em 1996 verificou que a redução da densidade celular endotelial corneana por essa técnica é pequena e, por conseguinte, segura ${ }^{(8)}$.

Nas publicações sobre a técnica de "quick chop" não se verifica menção à preservação de células endoteliais corneanas ou à comparação entre a redução da densidade celular endotelial da córnea entre as técnicas de "dividir e conquistar" e "quick chop"

Os objetivos do estudo foram verificar a perda de células endoteliais da córnea nos pacientes operados de catarata senil por facoemulsificação pelas técnicas de "dividir e conquistar" e "quick chop" e comparar e analisar a redução da densidade celular endotelial corneana entre os pacientes submetidos a essa técnica e à técnica de dividir e conquistar, modificada por Shepherd em 1990 ${ }^{(25)}$.

\section{MÉTODOS}

Este estudo foi realizado após aprovação pelo Comitê de Ética em Pesquisa HUCFF/UFRJ e todos os pacientes da amostra assinaram termo de consentimento livre e esclarecido.

A amostra do trabalho foi constituída por 56 pacientes, apresentando catarata senil grau 3 (núcleos de dureza moderada pela classificação de Emery $^{(28)}$, 1983, que vai de 1 a 5), selecionados prospectivamente no Ambulatório de Oftalmologia do HUCFF/UFRJ, agrupados seqüencialmente (o primeiro paciente no grupo 1 , o segundo no grupo 2, o terceiro no grupo 1 e assim sucessivamente) e submetidos à facoemulsificação endocapsular, através das técnicas de "dividir e conquistar" (28 pacientes, grupo 1) e "quick chop" (28 pacientes, grupo 2).

Incluímos pacientes com melhor acuidade visual corrigida igual ou pior que 0,4 , idade acima de 47 anos, sem deficiência mental e com densidade celular endotelial da córnea igual ou maior que 1.500 células $/ \mathrm{mm}^{2}$. Excluímos cataratas secundárias ou complicadas, pacientes diabéticos, córneas com "guttata", outras doenças oculares associadas (glaucoma, uveítes, traumas), usuários de lentes de contato, outras cirurgias oculares prévias, complicações per-operatórias e complicações pós-operatórias.

Foi realizado exame ocular completo pré e pós-operatório, incluindo acuidade visual com e sem correção, teste de motilidade ocular, biomicroscopia, tonometria de aplanação, mapeamento de retina e ceratometria, além de ecobiometria pré-operatória com planejamento para emetropia pós-operatória pela fórmula SRK-II.

O aparelho utilizado foi o Universal II da Alcon ${ }^{\circledR}$, com ponteira padrão de $30^{\circ}$. Foi realizada anestesia peribulbar (lidocaína a $2 \%$ e bupivacaína a $2 \%$ ). Usamos BSS com adrenalina $(0,5 \mathrm{mg}$ em $250 \mathrm{ml})$, metilcelulose a $2 \%$ e lente intra-ocular Acqua da Mediphacos ${ }^{\circledR}$. As substâncias usadas foram sempre da mesma marca. $O$ frasco de irrigação foi colocado cerca de $80 \mathrm{~cm}$ acima da cabeça do paciente. As incisões foram autoselantes corneanas de 3,2 $\mathrm{mm}$ e paracentese de $1 \mathrm{~mm}$ a $90^{\circ}$ da incisão. As cirurgias se modificaram apenas de acordo com a técnica escolhida para cada paciente. Os parâmetros utilizados nas cirurgias foram resumidos nas tabelas 1 e 2 . Após as cirurgias, foram feitos edema incisional e injeção subconjuntival de gentamicina e decadron e curativo oclusivo.

Foram anotados a técnica empregada, o volume de solução salina balanceada e o tempo de ultra-som utilizados em cada cirurgia.

Os exames de microscopia especular da córnea foram realizados no pré-operatório e pós-operatórios de 1 mês, 3 meses e 6 meses. Foi utilizado o aparelho computadorizado "Topcon SP2000P Non-Contact Specular Microscope", de não-contato, seguindo o seguinte método de contagem para aumentarmos a confiabilidade dos resultados: várias fotografias foram obtidas, e as 3 melhores selecionadas para análise. A média aritmética dos parâmetros foi determinada para cálculo do resultado final. Foi selecionado o maior número possível de células por fotografia, com um limite superior de 75 células. As células melhor delimitadas, nítidas e centrais, foram preferidas ${ }^{(29-31)}$.

Comparamos os grupos estatisticamente através dos testes "t" de Student para variável numérica, qui-quadrado para variável categórica, teste " $t$ ” pareado para comparar os resultados ao longo do tempo e o teste de correlação para verificar a relação do tempo de ultra-som e da idade com a perda endotelial e a paquimetria. $\mathrm{O}$ nível de significância foi fixado em $5 \%(\alpha=0,05)$.

\section{RESULTADOS}

Os grupos selecionados foram homogêneos quanto à idade (73,2 $\pm 5,8$ anos no grupo 1 e 69,6 69,5 anos no grupo 2, teste " $t$ " de Student $\mathrm{p}=0,097)$, à distribuição de olhos direito e esquerdo ( 15 olhos direitos ou 53,6\% e 13 olhos esquerdos ou $46,4 \%$ no grupo 1 e 14 olhos direitos e 14 olhos esquerdos ou $50 \%$ cada no grupo 2 , teste qui-quadrado $\mathrm{p}=0,705)$, à melhor acuidade visual pré-operatória $(0,27 \pm 0,09$ no grupo 1 e 


\begin{tabular}{|c|c|c|c|c|}
\hline \multicolumn{5}{|c|}{ Tabela 1. Parâmetros "dividir e conquistar" (grupo 1) } \\
\hline & Vácuo $(\mathrm{mmHg})$ & $\begin{array}{l}\text { Fluxo de aspiração } \\
(\mathrm{ml} / \mathrm{min})\end{array}$ & $\begin{array}{l}\text { Potência de } \\
\text { ultra-som (\%) }\end{array}$ & Modo \\
\hline Aspiração do córtex solto & 47 & 20 & 70 & cirurgião/linear \\
\hline Escultura do " $\mathrm{x}$ " & 1 & 20 & 70 & cirurgião/linear \\
\hline Facoaspiração dos quadrantes & $\begin{array}{c}151 \\
(<100 \text { final })\end{array}$ & 25 & 80 & $\begin{array}{c}\text { cirurgião/linear } \\
6 \text { pulsos/segundo }\end{array}$ \\
\hline
\end{tabular}

\begin{tabular}{|c|c|c|c|c|}
\hline & Vácuo (mmHg) & $\begin{array}{l}\text { Fluxo de aspiração } \\
(\mathrm{ml} / \mathrm{min})\end{array}$ & $\begin{array}{l}\text { Potência de } \\
\text { ultra-som (\%) }\end{array}$ & Modo \\
\hline $\begin{array}{l}\text { Aspiração do córtex solto e } \\
\text { fraturas iniciais }\end{array}$ & 200 & 28 & 80 & $\begin{array}{c}\text { cirurgião/linear } \\
2 \text { pulsos/segundo }\end{array}$ \\
\hline Facoaspiração dos fragmentos & $\begin{array}{c}151 \\
(<100 \text { final })\end{array}$ & 28 & 80 & $\begin{array}{c}\text { cirurgião/linear } \\
2 \text { pulsos/segundo }\end{array}$ \\
\hline
\end{tabular}

\begin{tabular}{|cccc|}
\hline \multirow{2}{*}{ Tabela 3. Redução da densidade endotelial percentual } \\
Grupo & \multicolumn{4}{c|}{$\boldsymbol{\Delta}$ Densidade endotelial central (\%) } \\
\cline { 2 - 4 } & Pré - 1 mês & $\mathbf{1}$ - $\mathbf{3}$ meses & $\mathbf{3}-\mathbf{6}$ meses \\
1 & $16,5 \pm 14,0$ & $-1,0 \pm 10,5$ & $-0,8 \pm 8,8$ \\
2 & $19,4 \pm 16,5$ & $-0,2 \pm 10,5$ & $-1,0 \pm 13,6$ \\
P entre os grupos & $\mathrm{p}=0,334$ & $\mathrm{p}=0,806$ & $\mathrm{p}=0,810$ \\
\hline
\end{tabular}

\begin{tabular}{|cccc|}
\hline \multirow{2}{*}{$\begin{array}{c}\text { Tabela 4. Redução da densidade endotelial numérica } \\
\text { Grupo }\end{array}$} & $\boldsymbol{\Delta}$ Densidade endotelial central & (Células $/ \mathbf{m m}^{2}$ ) \\
\cline { 2 - 4 } & \multicolumn{1}{c|}{ Pré - 1 mês } & $\mathbf{1}$ - $\mathbf{~ m e s e s}$ & $\mathbf{3}-\mathbf{6}$ meses \\
1 & $-392 \pm 373$ & $+28 \pm 208$ & $+18 \pm 176$ \\
2 & $-487 \pm 382$ & $+2 \pm 189$ & $+25 \pm 255$ \\
P entre os grupos & $\mathrm{p}=0,458$ & $\mathrm{p}=0,693$ & $\mathrm{p}=0,910$ \\
"t" pareado 1 & $\mathrm{P}<0,001$ & $\mathrm{p}=0,572$ & $\mathrm{p}=0,599$ \\
"t" pareado 2 & $\mathrm{P}<0,001$ & $\mathrm{p}=0,967$ & $\mathrm{p}=0,611$ \\
\hline
\end{tabular}

$0,27 \pm 0,10$ no grupo 2 , teste " $t$ " de Student $\mathrm{p}=0,885$ ) e à pressão intra-ocular $(14,1 \pm 3,3 \mathrm{mmHg}$ no grupo $1 \mathrm{e} 13,6 \pm 2,7 \mathrm{mmHg}$ no grupo 2, teste " $t$ " de Student $p=0,480$ ). Houve predominância do sexo feminino no grupo 2 ( 15 do sexo masculino ou $53,6 \%$ e 13 do sexo feminino ou $46,4 \%$ no grupo 1 e 9 do sexo masculino ou $32,1 \%$ e 19 do sexo feminino $67,9 \%$ no grupo 2 , teste qui-quadrado $\mathrm{p}=0,015$ ).

O exame do primeiro mês de pós-operatório mostrou uma melhora significativa da acuidade visual de $0,61 \pm 0,17$ no grupo 1 e $0,61 \pm 0,18$ no grupo 2 , teste "t" pareado $\mathrm{p}<0,001$ para ambos os grupos e semelhante entre os grupos, teste " $\mathrm{t}$ " de Student $\mathrm{p}=0,902$ e uma redução semelhante da pressão intraocular de 2,2 $\pm 3,7$ no grupo 1 e $2,3 \pm 2,5$ no grupo 2 , teste " $t$ " pareado $\mathrm{p}=0,003$ para o grupo 1 e $\mathrm{p}<0,001$ para o grupo $2 \mathrm{e}$ semelhante entre os grupos, teste "t" de Student $p=0,899$.

Verificamos que a técnica de "dividir e conquistar" utilizou 2,0 $\pm 0,7$ minutos de tempo de ultra-som e a de "quick chop" $1,1 \pm 0,5$ minuto (teste "t" de Student $\mathrm{p}<0,001$ ). Nos dois grupos o volume de solução salina balanceada utilizada foi semelhante, pois em cada grupo $12(42,9 \%)$ pacientes utilizaram menos de $200 \mathrm{ml}$ de solução e $16(57,1 \%$ ) pacientes mais de $250 \mathrm{ml}$ (máximo de $400 \mathrm{ml}$ ).

Em dias de pós-operatório, os exames de 1, 3 e 6 meses foram realizados em prazos semelhantes, de $34 \pm 6$ dias, $93 \pm 12$ dias e $185 \pm 14$ dias no grupo 1 e de $33 \pm 6$ dias, $94 \pm 09$ dias e $185 \pm 17$ dias no grupo 2 (todos os prazos semelhantes pelo teste "t" de Student, com p valor >0,05).

A densidade endotelial pré-operatória do grupo 1 foi de $2530 \pm 241$ e no grupo 2 foi de $2402 \pm 229$ e não havia diferença entre os grupos pelo teste " $\mathrm{t}$ " de Student $(\mathrm{p}=0,060)$.

A redução da densidade celular endotelial central da córnea foi significativa, em ambas as técnicas, no primeiro mês pós-operatório $\left(-392 \pm 373\right.$ células $/ \mathrm{mm}^{2}$ ou $16,5 \%$ no grupo $1 \mathrm{e}$ $-487 \pm 382$ células $/ \mathrm{mm}^{2}$ ou $19,4 \%$ no grupo 2 ) e as variações de densidade celular endotelial corneana subseqüentes, aos 3 e 6 meses, não foram significativas. Não houve diferença estatística na variação da densidade celular endotelial corneana ocorrida entre os grupos (teste " $\mathrm{t}$ " de Student, $\mathrm{p}=0,334 \mathrm{em}$ porcentagem ou $\mathrm{p}=0,458 \mathrm{em}$ células $/ \mathrm{mm}^{2}$; no $1 \stackrel{0}{\text { mês }}$ pós-operatório) (Gráfico 1).

Não houve correlação entre o $\Delta$ da densidade celular endotelial em 1 mês de pós-operatório e a idade do paciente $(r=-0,203)$, ou entre ele e o tempo utilizado de ultra-som $(\mathrm{r}=0,032)($ Gráficos 2 e 3).

A redução da densidade celular endotelial em 1 mês de pós-operatório entre os pacientes que utilizaram menos de $200 \mathrm{ml}\left(-410 \pm 354\right.$ células $\left./ \mathrm{mm}^{2}\right)$ e mais de $250 \mathrm{ml}(-466 \pm 401$ células $/ \mathrm{mm}^{2}$ ) de solução salina balanceada foi semelhante (teste " $\mathrm{t}$ " de Student $\mathrm{p}=0,664)$.

\section{DISCUSS $\tilde{A} O$}

Os grupos estudados puderam ser considerados homogêneos, exceto pela predominância de pacientes do sexo feminino no grupo 2. A diferença na distribuição por sexo não traz 


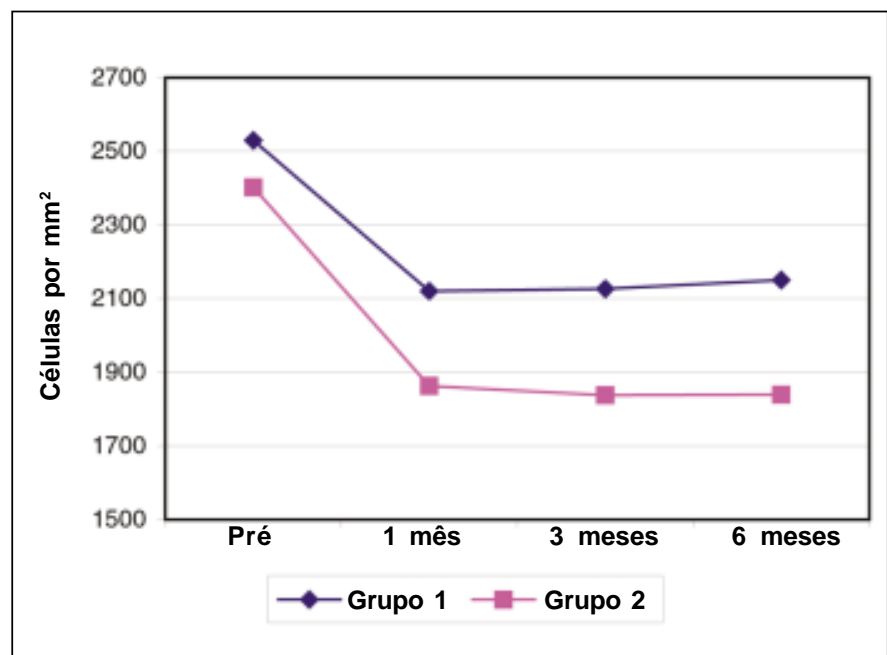

Gráfico 1 - Valores médios da densidade celular endotelial central (células por $\mathrm{mm}^{2}$ ); pré-operatório (Pré), pós-operatório de 1 mês (1 mês), pós-operatório 3 meses (3 meses) e pós-operatórios de 6 meses $(6 \mathrm{me}$ ses). Grupo 1 (dividir e conquistar) e grupo 2 ("quick chop")

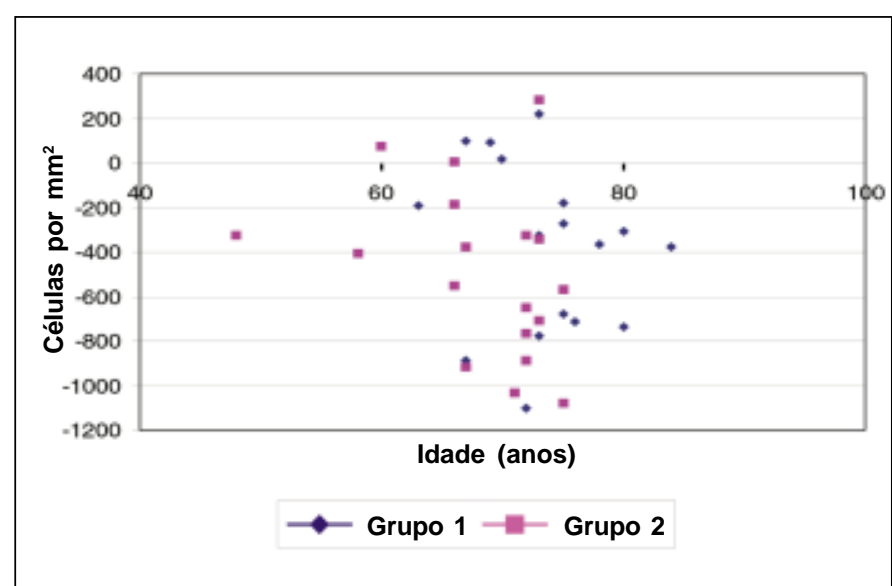

Gráfico 2 - Gráfico de dispersão mostrando a ausência de correlação entre o $\Delta$ da densidade celular endotelial em 1 mês (células por $\mathrm{mm}^{2}$ ) e a idade do paciente (anos)

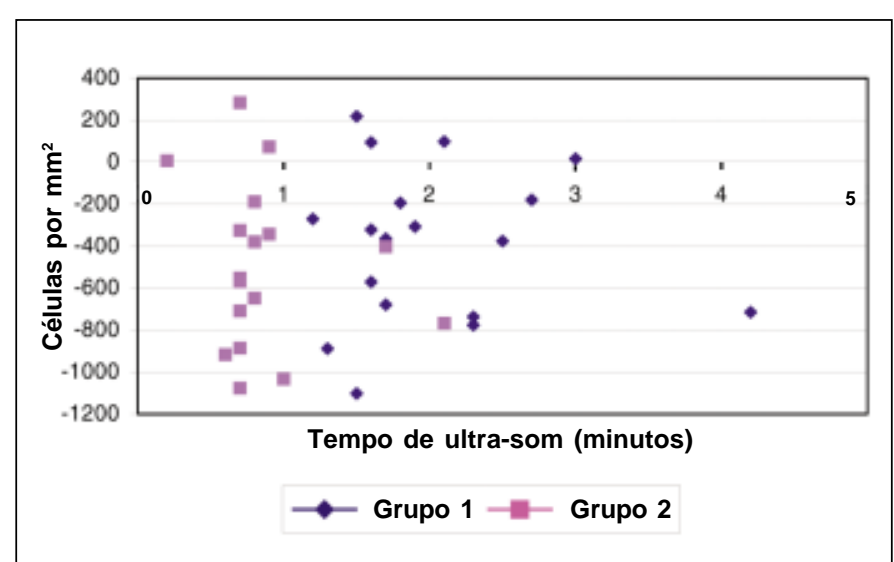

Gráfico 3. Gráfico de dispersão mostrando ausência de correlação entre $0 \Delta$ da redução da densidade celular endotelial em 1 mês (células por $\mathrm{mm}^{2}$ ) e o tempo utilizado de ultra-som (minutos) problemas para a amostra, pois não há diferença na densidade celular endotelial da córnea entre pacientes do sexo feminino e masculino ou na sua redução ao longo da vida(32).

As técnicas comparadas neste estudo se diferenciam principalmente pela maneira de fragmentar o cristalino. No grupo 1 (técnica de "dividir e conquistar" de Shepherd, 1990), a fratura ocorre após a confecção, às custas da vibração ultra-sônica da ponteira, de 2 sulcos centrais em cruz no núcleo, de espessura suficientemente tênue que permita a fratura do núcleo em 4 quadrantes, ao se impor, com a ponteira e a espátula, pressões laterais nos sulcos separando os quadrantes ${ }^{(25,33-35)}$. No grupo 2, "quick chop"(4-6), utiliza-se ultra-som por frações de segundos juntamente com vácuo elevado para apreender e reter o núcleo à ponteira. A fratura na técnica de "quick chop" é portanto mais rápida, por não exigir a confecção dos sulcos, tornando o uso total de ultra-som significativamente menor.

O aparelho que utilizamos nas cirurgias (Universal II) não conta com nenhum sistema moderno de controle do efeito "surge", que causa uma oscilação da câmara anterior, aproximando a córnea e a cápsula posterior da ponteira de ultra-som, podendo acarretar ruptura de cápsula posterior e perda de células endoteliais corneanas ${ }^{(2,34,36-37)}$.

$\mathrm{Na}$ apreensão do cristalino pela ponteira para ocasionar a fratura do núcleo na técnica de "quick chop", é necessário que se utilize vácuo elevado e alto fluxo de aspiração (nós utilizamos $200 \mathrm{mmHg}$ e $28 \mathrm{ml} / \mathrm{min})^{(4-6)}$. Após cada fratura, a ponteira de facoemulsificação sofreu uma desoclusão e causou efeito "surge". Ao menos 3 oscilações ocorreram a cada cirurgia, uma para fraturar o cristalino em 2 metades e as outras para separá-las em quadrantes. Não houve risco de lesão da cápsula posterior, pois o saco capsular estava preenchido por material cristaliniano, mas pode ter havido perda de células do endotélio corneano ${ }^{(2)}$.

Aparelhos modernos, com sistemas computadorizados de controle fluídico, permitem utilizar vácuo de até $500 \mathrm{mmHg}$ e fluxo de aspiração de $40 \mathrm{ml} / \mathrm{min}$ com estabilidade da câmara anterior. No aparelho que utilizamos, para podermos realizar a técnica de "quick chop" usamos vácuo e fluxo de aspiração bem menores; e mesmo assim convivemos com a instabilidade da câmara anterior. Precisamos reduzir ainda mais o vácuo após a fratura para proceder a facoemulsificação dos quadrantes de forma segura ${ }^{(1-3,37)}$. Na técnica de "dividir e conquistar", a escultura do núcleo é feita utilizando-se ultra-som elevado (70\%), fluxo de aspiração baixo (20 ml/min) e o menor vácuo possível (1 mmHg), pois não desejamos apreender nenhum fragmento de cristalino nesse momento ${ }^{(33-35)}$. Em ambas as técnicas utilizamos o modo pulsátil e vácuo entre 100 e $150 \mathrm{mmHg}$ para facoemulsificar os fragmentos de cristalino.

Na técnica de "dividir e conquistar" usamos mais tempo de ultra-som para a confecção dos sulcos, porém a ponteira trabalha afastada do endotélio, dentro do saco capsular, diminuindo o risco de lesão endotelial ${ }^{(2,25-26,34,36-38)}$.

Como trabalhamos no modo cirurgião/linear, a aferição da quantidade de energia de ultra-som empregada a cada cirurgia fica prejudicada, pois o tempo de ultra-som fornecido pelo 
aparelho é o tempo total de uso do pedal no estágio 3, e não sabemos se o uso por exemplo de 2,0 minutos de ultra-som foi a $50 \%$ ou a $80 \%$ da capacidade do aparelho, o que claramente corresponde a quantidades bem diferentes de energia. Os aparelhos mais modernos fornecem além do tempo de pedal, a quantidade de energia (em Joules) e a porcentagem de ultrasom empregadas ${ }^{(33-35)}$.

Para a proteção endotelial utilizamos a metilcelulose a $2 \%$. Ela tem baixo peso molecular, é dispersiva, pouco pseudoplástica e não forma ligação química com a camada de células endoteliais. Permanece na câmara anterior por mais tempo que viscoelásticos coesivos, porém substâncias de alto peso molecular protegem mais o endotélio ao ocupar melhor o espaço da câmara anterior e substâncias compostas por hialuronato de sódio travam ligações químicas com o ácido hialurônico das células endoteliais, formando um colchão protetor do endotélio $^{(39-41)}$.

O alto fluxo de aspiração gera maior turbilhonamento de líquido na câmara anterior e remove mais rapidamente o viscoelástico, assim no "quick chop" a Metilcelulose a $2 \%{ }^{\circledR}$ é removida mais prontamente do que em "dividir e conquistar". O turbilhonamento é considerado uma causa de perda endotelial na facoemulsificação ${ }^{(17)}$.

Outra maneira indireta de aferirmos o turbilhonamento é verificando a quantidade de BSS utilizadas nas técnicas. O número de pacientes que utilizou até $200 \mathrm{ml}$ (12) e acima de $250 \mathrm{ml}$ (16) foi o mesmo nos grupos 1 e 2 . Assim, uma técnica não precisou de mais infusão do que a outra.

Apesar de conhecermos as limitações do aparelho e do viscoelástico utilizados, procuramos selecionar uma amostra homogênea de pacientes, com córneas saudáveis e de densidade celular endotelial normal, e utilizamos os mesmos materiais (bisturis, viscoelásticos, solução salina balanceada e lente intra-ocular) em todas as cirurgias. Somente alteramos nos dois grupos as técnicas cirúrgicas.

Observamos que a perda celular endotelial foi similar entre as técnicas. Porém o número e a porcentagem de células perdidas se mostraram maiores no grupo 2. Como o desvio padrão desses valores foi alto, os cálculos estatísticos não descartaram a hipótese da diferença ser causada pelo acaso.

A perda celular endotelial da córnea por facoemulsificação se dá devido a diversos fatores, nem todos facilmente mensuráveis ${ }^{(17)}$. O dano ao endotélio se inicia com a incisão, e se segue durante a cirurgia com o volume, a qualidade da solução de irrigação e a turbulência de líquido no interior da câmara anterior, além dos microtraumatismos causados pelos instrumentos e fragmentos de cristalino dentro do olho e pelo implante da lente intra-ocular.

O tempo e quantidade de ultra-som utilizados na cirurgia vêm sendo bastante discutidos e estudados como causadores de danos endoteliais corneanos. Alguns autores referiram que não se encontrou correlação entre perda celular endotelial e tempo de ultra-som, ou entre ela e o tempo ou volume de irrigação, e que as perdas celulares endoteliais devem ser causadas por fatores como instrumentos e manobras intraoculares. Além disso, relataram que a posição da ponteira de facoemulsificação em relação ao olho (câmara anterior ou posterior) pode determinar maior ou menor lesão endotelial. A facoemulsificação na câmara anterior, ainda segundo esses autores, causa maior perda celular endotelial ${ }^{(17)}$. Escolhemos neste estudo cataratas semelhantes em consistência, para que a dificuldade de remoção fosse semelhante e apenas as técnicas variassem. Já sabíamos que a técnica de "quick chop" costumava utilizar menos ultra-som, e consequentemente, a cirurgia era mais rápida. Acreditávamos que isto pudesse causar uma menor perda celular endotelial.

As técnicas endocapsulares como a de "dividir e conquistar" de Shepherd em 1990, trouxeram uma redução significativa do tempo de ultra-som necessário para remoção completa do cristalino $^{(25)}$. Crema em 1996, citou o uso nesta técnica de 2,2 a 4,9 minutos de ultra-som para remover cataratas de graus 2 ou $3^{(8)}$.

Assim, o uso de até 4 a 5 minutos de ultra-som para se remover o cristalino, de preferência por técnica endocapsular ou ao nível da íris, e com o uso de substâncias viscoelásticas, causa menos perda endotelial ${ }^{(8,23-24)}$.

Como nas nossas cirurgias utilizamos, em média, 2,0 minutos de ultra-som no grupo 1 e 1,1 minuto de ultra-som no grupo 2, bem abaixo do tempo limite considerado seguro de ultra-som, talvez os outros fatores implicados na perda celular endotelial por facoemulsificação tenham sido mais determinantes nas nossas cirurgias, pois a redução da densidade celular endotelial da córnea foi semelhante entre os grupos. Da mesma forma, não verificamos correlação entre o tempo de ultra-som utilizado e a variação da densidade celular endotelial em 1 mês.

Não verificamos correlação entre a idade do paciente e a variação da densidade celular endotelial em 1 mês. Talvez por termos selecionado pacientes na mesma faixa etária, com endotélios saudáveis e com boa contagem endotelial.

Outro fator relacionado à lesão endotelial corneana em diversos trabalhos foi a qualidade e volume de solução salina balanceada utilizada. Como a qualidade foi a mesma, pois utilizamos sempre a mesma marca, dividimos os pacientes em 2 grupos, aqueles que utilizaram mais $(\geq 250 \mathrm{ml})$ ou menos ( $\leq 200 \mathrm{ml}$ ) solução durante a cirurgia. Não verificamos diferença na variação da paquimetria corneana ou na variação da densidade celular endotelial da córnea em 1 mês de pós-operatório, entre os dois grupos. O volume infundido no grupo que utilizou mais de $250 \mathrm{ml}$ não ultrapassou $400 \mathrm{ml}$, volume que pode não ter sido grande o suficiente para causar maior perda celular endotelial.

Ao selecionarmos nossa amostra de pacientes, excluímos córneas com alterações pré-operatórias do endotélio e olhos com qualquer complicação per ou pós-operatória. O local, tamanho e instrumental utilizado para a incisão também foi o mesmo e utilizamos a mesma lente intra-ocular, implantada da mesma forma.

Outros fatores implicados na lesão endotelial por facoemulsificação, como o trauma mecânico pelo instrumental e fragmentos do cristalino, a ocorrência de bolhas de ar, a turbu- 
lência de solução salina balanceada na câmara anterior e a oscilação da câmara anterior com o efeito "surge" não são passíveis de ser quantificados e, talvez, tenham sido determinantes na maior (apesar de não estatisticamente significativa) perda endotelial no grupo 2.

Além disso, é conveniente lembrarmos que os aparelhos e viscoelásticos mais modernos tornam as cirurgias com alto fluxo e vácuo mais seguras e confortáveis para o cirurgião, provavelmente reduzindo o turbilhonamento líquido, o efeito "surge" e mesmo o tempo de ultra-som, e um estudo semelhante em tais condições poderiam fornecer resultados favoráveis à técnica de "quick chop".

Nosso estudo mostra que mesmo em aparelhos menos sofisticados e com viscoelásticos menos protetores, se seguirmos determinados cuidados nos parâmetros e técnica empregados, é possível obter com as novas técnicas de facoemulsificação, de alto fluxo e vácuo, a mesma segurança já obtida por outros autores com a técnica de "dividir e conquistar". Acreditamos que esta conclusão é importante, pois na realidade nacional nem sempre os aparelhos mais modernos estão à disposição dos cirurgiões.

\section{CONCLUSÃO}

A redução da densidade celular endotelial da córnea foi significativa no primeiro mês pós-operatório e não variou significativamente aos 3 e 6 meses pós-operatórios. Ela foi de $16,5 \%$ na técnica de "dividir e conquistar" e de $19,4 \%$ na técnica de "quick chop".

Apesar da maior redução de densidade celular endotelial corneana ter ocorrido nos pacientes operados pela técnica de "quick chop", a diferença não foi estatisticamente significativa.

Concluímos que ambas as técnicas causaram redução semelhante da densidade endotelial corneana central da córnea.

\section{ABSTRACT}

Purpose: Since one of the most implicated factors in corneal endothelial cell loss after phacoemulsification is the ultrasound time, and that the "quick chop" technique utilizes less ultrasound time, the objective of this study was to compare and analyze the reduction of the central corneal endothelial cell density between the patients submitted to the "divide and conquer" and "quick chop" techniques. Methods: Fifty-six patients with grade 3 senile cataract were prospectively selected and submitted to endocapsular phacoemulsification by the "divide and conquer" (28 patients, group 1) and "quick chop" (28 patients, group 2) techniques. The non-contact corneal central specular microscopy performed pre- and postoperatively at one month, 3 months and 6 months, and the ultrasound time used for each surgery, were verified. Results: We observed that the "divide and conquer" technique spent an average of 2.0 minutes of ultrasound time and the "quick chop", 1.1 minute; that the reduction of the central corneal endothelial cell density was significant for both techniques in the first postoperative month (16.5\% in group 1 and $19.4 \%$ in group 2) and that the variations in central corneal endothelial cell density that followed, at the $3^{\text {rd }}$ and $6^{\text {th }}$ month were not significant. There was no statistically significant difference between the variation of the central corneal endothelial cell density that occurred with both techniques (Student's " $\mathrm{t}$ " test $\mathrm{p}=0.334$; in the $1^{\text {st }}$ postoperative month). Conclusions: We concluded that the reduction of central corneal endothelial cell density was not statistically different between the two techniques.

Keywords: Cataract extraction/methods; Phacoemulsification; Cell count; Endothelium, Corneal; Comparative study

\section{REFERÊNCIAS}

1. Guttman C, Fine IH. Novos aparelhos de faco estabelecem novos padrões para catarata. Ophthalmol Times Am Latina 2000;4(1):14-6.

2. Kwitko S. Endotélio e cirurgia de catarata: grandes desafios. Arq Bras de Oftalmol. 2000;63(3):235-9.

3. Vieira M. A terceira geração em aparelhos de facoemulsificação. Oftalmologia Foco 2000;67:53-4.

4. Dillman DM. Techniques, thoughts, challenges. In: Fine, I.H. Clear corneal lens surgery. Thorofare: Slack.; 1999.

5. Dillman DM. Endocapsular phaco quick chop. In: Masket S, Crandall AS Atlas of cataract surgery. London: Martin Dunitz; 1999.

6. Crema AS. O meu jeito de realizar facoemulsificação. In: Centurion V. Faco total. $2^{\underline{a}}$ ed. Rio de Janeiro: Cultura Médica; 2000.

7. Nagahara KB. Phaco chop. [video]. San Francisco: American Society of Cataract and Refractive Surgery 1993.

8. Crema AS. Estudo comparativo do astigmatismo corneano induzido a da perda de células endoteliais após facoemulsificação por incisões auto-selantes escleral superior e corneana temporal [tese]. Rio de Janeiro: Universidade Federal do Rio de Janeiro; 1996.

9. Ravalico G, Tognetto D, Palomba M A, Lovisato A, Baccara F. Corneal endothelial function after extracapsular cataract extraction and phacoemulsification. J. Cataract Refract Surg.1997;23(7):1000-5.

10. Stumpf S. Extração extracapsular vs. facoemulsificação em cataratas duras. Oftalmol Foco. 2000;68:21.

11. Binder PS, Sternberg H, Wickham MG, Worthen DM. Corneal endothelial damage associated with phacoemulsification. Am J Ophthalmol. 1976;82(1): 48-54.

12. Bourne WM, Nelson LR, Hodge DO. Continued endothelial cell loss ten years after lens implantation. Ophthalmology. 1994;101(6):1014-22; discussion 1022-3.

13. Irvine AR, Kratz RP, O'Donnell JJ. Endothelial damage with phacoemulsification and intraocular lens implantation. Arch. Ophthalmol. 1978;96(6): 1023-6.

14. Galin MA, Lin LL, Fetherrolf E, Obstbaum SA, Sugar A. Time analysis of corneal endothelial cell density after cataract extraction. Am J Ophthalmol. 1979;88(1):93-6.

15. Olsen T, Gimbel H. Phacoemulsification, capsulorhexis, and intraocular lens power prediction accuracy. J Cataract Refract Surg. 1993;19(6):695-9.

16. Schultz RO, Glasser DB, Matsuda M, Yee RW, Edelhauser HF. Response of the corneal endothelium to cataract surgery. Arch Ophthalmol 1986;104(8): 1164-9.

17. Schmitt-Bernard CF, Arnaud B. Factors of endothelial cell loss during phacoemulsification. Update. J Fr Ophtalmol. 1997;20(8):628-39. Francese.

18. Krey H. Ultrasonic turbulences at the phacoemulsification tip. J Cataract Refract Surg. 1989;15(3):343-4.

19. Sugar J, Mitchelson J, Kraff M. The effect of phacoemulsification on corneal endothelial cell density. Arch Ophthalmol. 1978;96(3):446-8.

20. Weiser M. Phacoemulsification endocapsulaire. Ophthalmologie. 1990;4:454-5.

21. Werblin TP. Long-term endothelial cell loss following phacoemulsification: model of evaluating endothelial damage after intraocular surgery. Refract Corneal Surg. 1993;9(1):29-35. 
22. Zetterstrom C, Laurell CG. Comparison of endothelial cell loss and phacoemulsification energy during endocapsular phacoemulsification surgery. J Cataract Refract Surg. 1995;21(1):55-8.

23. Gimbel HV. Divide and conquer nucleofractis phacoemulsification: development and variations. J Cataract Refract Surg. 1991;17(3):281-91.

24. Domingues FGP, Crema AS, Yamane Y. Complicações intra-operatórias da facoemulsificação durante a residência médica. Rev Bras de Oftalmol. 2000; 59(4):275-9.

25. Shepherd JR. In situ fracture. J Cataract Refract Surg. 1990;16(4):436-40.

26. Hayashi K, Nakao F, Hayashi F. Corneal endothelial cell loss after phacoemulsification using nuclear cracking procedures. J Cataract Refract Surg. 1994; 20(1):44-7.

27. Domingues FGP, Moraes Junior HV, Yamane R. Avaliação da perda de células endoteliais da córnea após facoemulsificação durante a transição da técnica de "dividir e conquistar" para a técnica de "quick chop". Rev Bras de Oftalmol. 2003;62(3):212-8.

28. Emery JA. Patient selection. Kelman phacoemulsification. In: Emery JM, Mc Intyre DJ. Extracapsular cataract surgery. London: The C.V. Mosby; 1983.

29. Cheng H, Jacobs PM, McPherson K, Noble MJ. Precision of cell density estimates and endothelial cell loss with age. Arch Ophthalmol. 1985;103(10): 1478-81.

30. Hirst LW, Yamauchi K, Enger C, Vogelpohl W, Whittington V. Quantitative analysis of the wide-field specular microscopy. II. Precision of sampling from the central corneal endothelium. Invest Ophthalmol Vis Sci. 1989;30(9):1972-9.
31. Rodrigues FLMX. Microscopia especular da córnea pela técnica de não contato: análise paramétrica e de confiabilidade [tese]. Rio de Janeiro: Universidade Federal do Rio de Janeiro; 1999.

32. Speedwell L, Novakovic P, Sherrard ES, Taylor, DS. The infant corneal endothelium. Arch Ophthalmol, 1988;106(6):771-5.

33. Fine IH, Maloney WF, Dillman DM. Crack and flip phacoemulsification technique. J. Cataract Refract Surg. 1993;19(6):797-802.

34. Ghiaroni A. Seção de facoemulsificação. Rev Bras Oftalmol, 1995;54(1):73-5.

35. Lopez VB. Facoemulsificação com regulagem única diminui o risco de lesão ao tecido durante a cirurgia de catarata. Ocular Surg News Latin Am. 2000;5:5.

36. Mendonça BD. Princípios dos equipamentos de facoemulsificação. Oftalmol Foco. Encarte 1993;10:32.

37. Daher L, Ghiaroni A. Considerações sobre o funcionamento dos diferentes aparelhos de facoemulsificação. Seção de facoemulsificação. Rev Bras de Oftalmol. 1994;53(1):83-5.

38. Pacifico RL. Divide and conquer phacoemulsification. One-handed variant. J Cataract Refract Surg. 1992;18(5):513-7.

39. Arshinoff AS, Olson RJ, Fine IH, Serrafano D, McDermoott ML, Kreaff M, Hoffman J. A nova ciência e aplicações clinicas dos viscoelásticos. Ocular Surg News Ed Int. 1999.

40. Monson MC, Tamura M, Mamalis N, Olson RJ, Olson RJ. Protective effects of healon and occucoat against air bubble endothelial damage during ultrasonic agitation of the anterior chamber. J Cataract Refract Surg. 1991;17(5): 613-6.

41. Ravalico G, Tognetto D, Baccara F, Lovisato, A. Corneal endothelial protection by different viscoelastics during phacoemulsification. J Cataract Refract Surg. 1997;23(3):433-9.

\section{SINCLIO - Simpósio Internacional de Catarata e Lente Intra-ocular}

\section{1 e 12 de Março de 2005}

Centro de Convenções do IEP (Hospital Sirio Libanês) - São Paulo - SP

\section{PRO MOÇÃO: Seminário Oftalmológico da UNICAMP}

\section{IN FO RMAÇÕES: ZTL Brasil Eventos}

Fone/ Fax: (11) 3817-4091 e 3812-0186

E-mail: ztlbrasil@ ztlbrasil.com.br 